\title{
Experiments of Color Contrast on Excised Frog Eyes.
}

By

Köiti Motokawa and Kituya Iwama.

(本川弘 $\rightarrow$ )

(岩間 吉也)

(From the Physiological Laboratory of Prof. K. Miotokawa, Tohoku University, Sendai.)

(Received for publication, April 20, 1949)

As reported in our preceding papers, ${ }^{122}$ the excitability curve which represents the time course of electrical excitability of the retina after a brief illumination, shows generally three distinct humps R, G and B (see Fig. 1). In the present paper, we deal with the effect of colored light which precedes white light upon the excitability curve for the white light. The procedure of experimentation is shown schematically in the insets of Fig. 1, where the notation b-g. represents bluish green light, r-y. reddish yellow, Wh. white light and S electrical stimulation of one second in duration.

As can be seen in the figure, bluish green light preceding white one enhances selectively the $\mathrm{R}$ process, and reddish yellow light preceding white light increases mainly the $\mathrm{B}$ process. We know that red light alone gives rise to the $\mathrm{R}$ process. ${ }^{2)}$ Therefore, the selective enhancement of the $R$ process stated above must be so interpreted that bluish green light succeeded by white light has caused a retinal

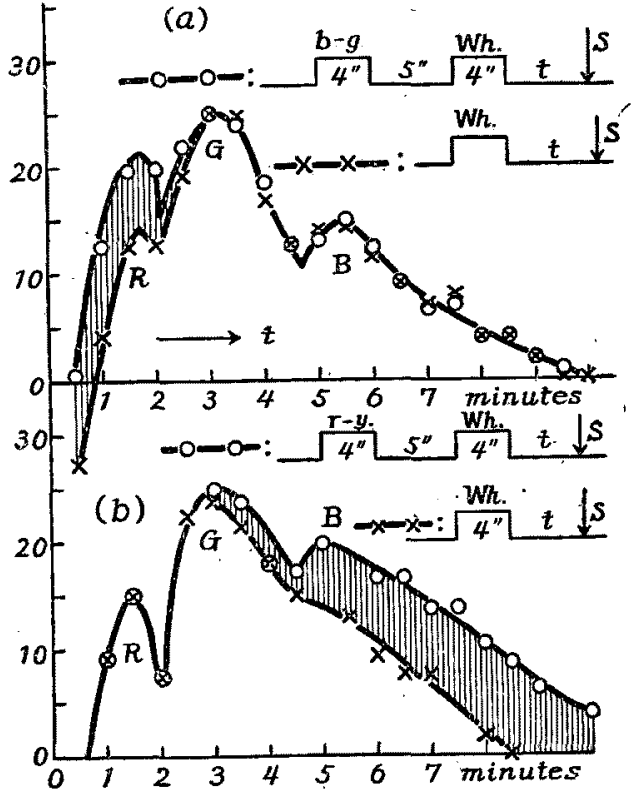

Fig. 1. Explanation in the text. change underlying a red sensation. The above findings, therefore, furnish us with physiological evidence of successive color contrast.

\section{Literature.}

(1) Motokawa, K. and Iwama, K., This Journal, 1949, 50, 240.

(2) Motokawa, K. and Iwama, K., Ibid., 1949, 50, 258. 